\title{
Location Management for Mobile Commerce Applications in Wireless Internet Environment
}

\author{
UPKAR VARSHNEY \\ Georgia State University
}

\begin{abstract}
With recent advances in devices, middleware, applications and networking infrastructure, the wireless Internet is becoming a reality. We believe that some of the major drivers of the wireless Internet will be emerging mobile applications such as mobile commerce. Although many of these are futuristic, some applications including user-and location-specific mobile advertising, locationbased services, and mobile financial services are beginning to be commercialized. Mobile commerce applications present several interesting and complex challenges including location management of products, services, devices, and people. Further, these applications have fairly diverse requirements from the underlying wireless infrastructure in terms of location accuracy, response time, multicast support, transaction frequency and duration, and dependability. Therefore, research is necessary to address these important and complex challenges. In this article, we present an integrated location management architecture to support the diverse location requirements of $\mathrm{m}$-commerce applications. The proposed architecture is capable of supporting a range of location accuracies, wider network coverage, wireless multicast, and infrastructure dependability for $\mathrm{m}$-commerce applications. The proposed architecture can also support several emerging mobile applications. Additionally, several interesting research problems and directions in location management for wireless Internet applications are presented and discussed.
\end{abstract}

Categories and Subject Descriptors: C.2.1 [Computer-Communication Networks]: Network Architecture and Design-wireless communication

General Terms: Applications, Performance

Additional Key Words and Phrases: Mobile commerce, location management, wireless Internet, wireless LANs, satellites, wireless multicast, mobile applications, infrastructure dependability

\section{INTRODUCTION}

The wireless Internet has received significant interest among carriers, vendors, applications developers and users. In addition to wireless access to the Internet, it must deal with the adaptation of protocols and applications to the limitations of devices and wireless networks [Goodman 2000]. Although several different

This research was supported, in part, by a research grant from the Robinson College of Business of Georgia State University.

Author's addresses: Department of Computer Information Systems, Georgia State University, Atlanta, GA 30302-4015; email: uvarshne@cis.gsu.edu.

Permission to make digital or hard copies of part or all of this work for personal or classroom use is granted without fee provided that copies are not made or distributed for profit or direct commercial advantage and that copies show this notice on the first page or initial screen of a display along with the full citation. Copyrights for components of this work owned by others than ACM must be honored. Abstracting with credit is permitted. To copy otherwise, to republish, to post on servers, to redistribute to lists, or to use any component of this work in other works requires prior specific permission and/or a fee. Permissions may be requested from Publications Dept., ACM, Inc., 1515 Broadway, New York, NY 10036 USA, fax: +1 (212) 869-0481, or permissions@acm.org.

(C) 2003 ACM 1533-5399/03/0800-0236 $\$ 5.00$

ACM Transactions on Internet Technology, Vol. 3, No. 3, August 2003, Pages 236-255. 


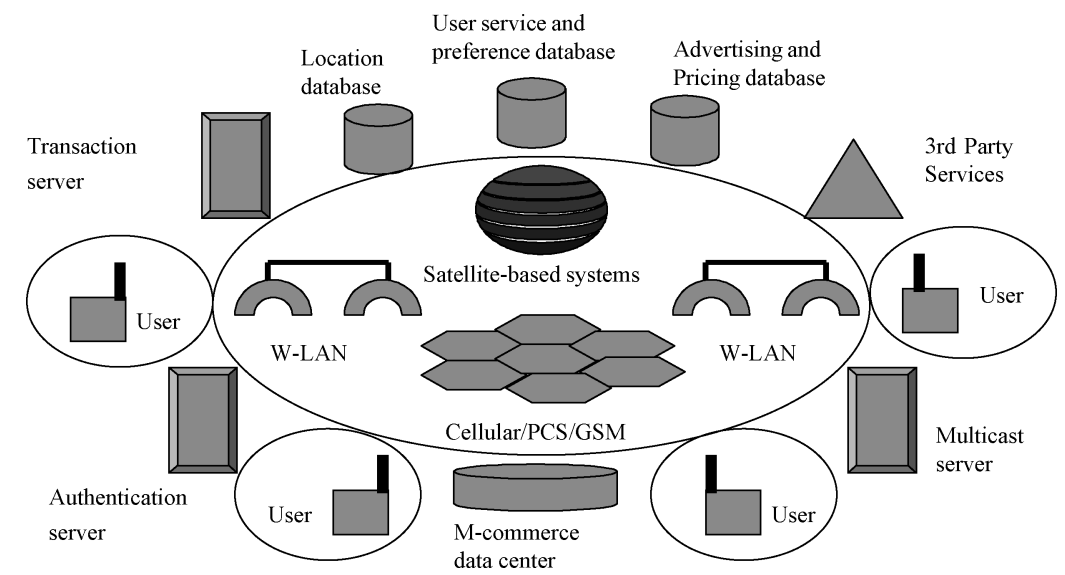

Fig. 1. A possible architecture for the wireless Internet.

configurations are possible, we believe that the wireless Internet should include devices and user interfaces, wireless infrastructure, mobile middleware, servers, and databases (Figure 1). In such an environment, a typical transaction consists of multiple steps involving several components. A user's request is forwarded to a transaction server, which checks with an authentication server. Once authenticated, preference and pricing databases are accessed. Also, to locate other users and servers, a location database is contacted. If the transaction requires setting up a group session involving multiple users, then a multicast server is also contacted. Certain transactions require accessing a data center and additional third party services, such as location tracking by other providers.

Although the architecture shown in Figure 1 corresponds to an infrastructure-oriented wireless network, the transactions could also be supported in ad hoc wireless networks, where users, devices, and servers could all be mobile. One or more nodes (devices or servers) can dynamically be selected to act as group leaders based on mobility levels and their ability to locate other required servers. In an ad hoc wireless network, completing a complex and possibly long session before a component moves out of range is a challenging task and certainly more work then is necessary to address transactions in ad hoc wireless networks.

We believe that one of the major drivers of the wireless Internet will be mobile commerce, which includes many new applications that become possible only due to wireless infrastructure (such as location-based services) in addition to e-commerce applications modified for wireless environment. It is estimated that the market of several hundred billion dollars for m-commerce will exist in the next few years.

As mobile commerce is an emerging area, there has been limited work in addressing a range of complex issues. This includes a classification of applications [Varshney et al. 2000], a 4-layer framework and a detailed treatment of $\mathrm{m}$-commerce issues [Varshney and Vetter 2002], and location issues and implementation experiences [Cousins and Varshney 2001, Varshney 2001]. 
Although there are several possible m-commerce applications [Varshney and Vetter 2002], only a few of these applications have been offered by providers thus far. These include preliminary versions of mobile financial services, mobile advertising, and location-aware services. Advanced versions of these applications will require location information of users, devices, servers, products, and services. These applications also have widely different location precision, response time, and scalability requirements. Also, more work is necessary to evaluate location overhead under different mobility patterns, transaction rates, and network size. There has been very little work in this area, but we would like to briefly overview the related work in location-based services.

An interesting implementation of location-based discovery of services includes mapping current location of a user to an area in Cellular Packet Digital Data (CDPD) and then searching services in the area [Rastimor at el. 2001]. Another service discovery, based on mapping of bookmarks to Universal Resource Locator (URL) of services in the current location of user, is presented in Sastry et al. [2001]. A secure location service using context and location awareness is presented in Bisdikian et al. [2001].

In this article, we present an integrated location management architecture that has been designed to support the diverse location requirements of both current as well as future m-commerce applications. This proposed architecture is capable of supporting a range of location accuracies, network coverage, and, wireless multicast and dependability requirements of m-commerce applications.

Major contributions of this article are (a) requirement analysis of locationintensive mobile commerce applications and (b) design of an integrated location management architecture for m-commerce applications. We have also identified several interesting research problems, directions, and possible solutions in location management for m-commerce.

The article is organized as follows: In Section 2 , we discuss three $m$-commerce applications and specific location requirements. In Section 3, we present our location management architecture. In Section 4, we show how the proposed architecture may be applied to support future $m$-commerce applications. We present several research issues and future directions in Section 5 and some concluding remarks in Section 6.

\section{LOCATION-INTENSIVE M-COMMERCE APPLICATIONS AND REQUIREMENTS}

Several m-commerce applications have been proposed in the literature [Varshney and Vetter 2002]; however, only some of these have been offered by wireless providers so far. In this section, we discuss three current m-commerce applications that require location support. These location-intensive applications are:

- Mobile financial applications

- Mobile advertising

-Location-based services.

ACM Transactions on Internet Technology, Vol. 3, No. 3, August 2003. 


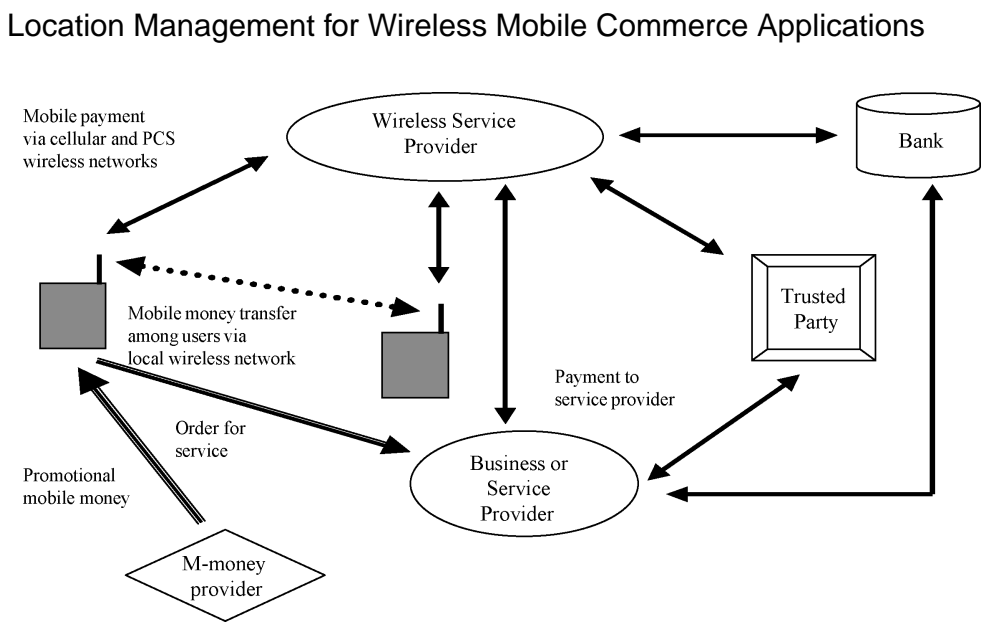

Fig. 2. Mobile financial applications.

\subsection{Mobile Financial Applications}

Mobile Financial Applications consist of mobile banking and brokerage services, mobile money transfer, and mobile payments. These applications could transform a mobile device into a business tool, replacing bank, ATM, and credit cards by letting a user conduct financial transactions with mobile money. It is projected that the number of users making mobile payments will reach to a total of 285 million in Western Europe, Asia and North America by 2005. Out of these, about 53 million users are expected to have a mobile wallet [Allnetdevices, 2002].

Several mobile financial applications are shown in Figure 2. A mobile user attempts to purchase goods or services from a business or service provider, which then contacts a trusted third party, the wireless service provider, or a financial institution to authenticate the user and amount of purchase. Once approved, a mobile payment can be made and the purchase is completed. The corresponding funds can then be withdrawn from user's m-wallet, charged to user's phone bill, or subtracted from user's bank account. Alternatively, the user could pay using "mobile money" provided to him/her by another user or a third party mobile money provider. Mobile money can be moved freely among users either by using a local area wireless network or by using the wireless service provider's network.

Two other requirements of mobile financial applications are support for mobile payments and secure transactions. Several groups are already working on mobile payments, including PayCircle that is established by HP, Lucent, Oracle, Sun, and Siemens [Varshney 2002]. Mobile payments can be divided into macro-(more than $\$ 10$ ) and micro-payments (less than or equal to $\$ 10$ ). Micro-payments can be implemented in several ways: first, a user could make a toll call equal to the cost of item, as used by SONERA in Finland for wireless vending service. Second is to buy prepaid numbers from a service provider, bank, or credit card company, as used in PayPal for mobile money transfer. For mobile payment providers, there are issues, such as the transaction cost of mobile micro-payments, and ways to make some profit on mobile micro-payments. 
First, service providers could require prepayments by users. Also, the cost of micro-payments decreases with an increased number of transactions. A provider can also offer mobile payment service as a competitive feature, resulting in an increase in customers and overall revenues.

There are several mobile payment providers, including wireless provider Vodafone's service in England, Germany, and Italy [Vodafone 2002]. Expected to reach to all of its 50 million customers by late 2003, the mobile payment service is based on user and device authentication, and e-wallet processing. Another payment service to businesses and customers has been started by Paybox using its own proprietary architecture [Paybox 2002]. To support mobile payments across multiple operators, Sprint and eONE have initiated a mobile payment network that will allow users to make mobile payments nationwide [Sprint 2002]. By using PaymentWorks, the same software used by several providers in Europe, the network can even allow international payments. Several financial companies and vendors are implementing end-to-end transaction support for financial applications [FSTC 2002]. Some current work on mobile cash withdrawal and change return can be found in Tracz and Wrona [2001].

Mobile financial transactions require a strong level of security support. Although, security features have been added in mobile middleware such as WAP, end-to-end security is still a problem [Ghosh and Swaminatha 2001]. Endto-end security support will become possible with the wide scale deployment of WAP 2.0. For financial applications, wireless PKI (Public Key Infrastructure), a system to manage keys and certificates, can be used to authenticate and obtain digital signatures from mobile users. In Japan, a few simple mobile financial applications are currently supported for iMode phones using KVM, a version of Java designed for small devices. Security is provided by SSL (Secure Socket Layer), both 40 and 128 bit versions [Varshney 2002].

\subsection{Mobile Advertising}

By keeping track of user's purchasing habits and current location, a very targeted advertising campaign can be performed. In one possible scenario (shown in Figure 3), mobile users are informed about various on-going specials. Messages can be sent to all users who are currently in a certain area (identified by advertisers or even by users) or to certain users in all locations. Depending on interests and personality types of individual users, advertisers could decide whether a "push" or "pull" form of advertising is more suitable. As more wireless bandwidth becomes available, content-rich advertising can be produced for individual users with specific needs, interests, and inclinations [Varshney and Vetter 2002]. It has been demonstrated in several trials that mobile users are willing to receive advertising messages with incentives.

From wireless service provider's view, several factors including the size of advertising messages, number of customers targeted and the value of items can be used to determine how to charge for mobile advertising. It should be noted that there are major issues of privacy and sharing of user information with other providers. We believe that an "opt-in" approach should be implemented where explicit user permission is obtained before "pushing" any advertising 


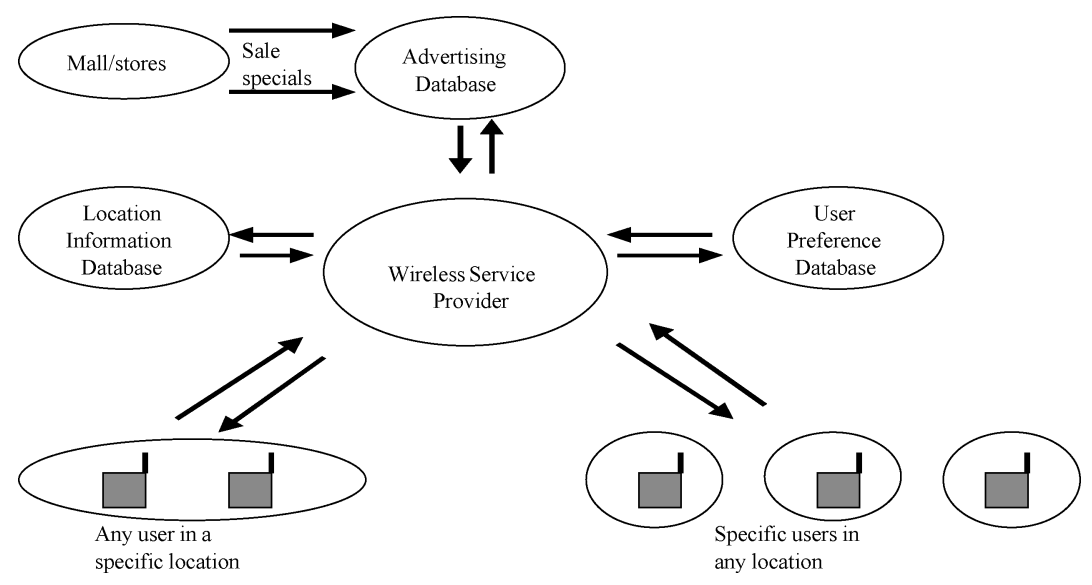

Fig. 3. A possible scenario for mobile advertising.

content. Cellular Telephony and Internet Association (CTIA) has requested that the FCC approve its "opt-in" policy for mobile advertising.

There has been some progress on mobile advertising. Mobile advertisements with coupons for a fast food chain have been tested by SMS-Rabatt [Fichtner 2002]. It has been considered quite successful as more than $3.5 \%$ of coupons were utilized as lunch-time messages were sent to interested users, resulting in very targeted and timed mobile advertising. Pepsi Co. has created an advertisement using "Pepsi Foot", a game where mobile users select a soccer team to play with other virtual teams [Diercks 2001]. Many wireless carriers including AT\&T wireless, BT Cellnet, and Vodafone are offering mobile advertisements using opt-in approach. In Japan, several portals are pushing simple advertising contents to iMode phone users. To create a uniform set of guidelines for wide scale use of mobile advertising, the Wireless Advertising Association and Wireless Marketing Association have merged, thereby bringing many players in mobile advertising together including Unilever, AOL, Nokia, Orange, Vodafone, and Lycos [Mobile Marketing Association 2001].

\subsection{Location-based Services}

These services utilize a user's location to provide location-aware content including information on restaurants, devices, users, and products. Location-based services can be offered in both "pull" and "push" modes. For example, one user might be interested in knowing the availability and waiting time at one or more restaurants close to her current location (pull). Another user might like to be informed when one of his friends is located in the same general area (push).

In general, these services require location tracking of fixed, portable and mobile entities. Location information of all fixed entities can be kept in a separate database for each area, while location tracking of mobile and portable entities could be performed on-demand. When a mobile user enters an area, the list of services and location information can be provided based on current preferences and/or the history of choices. 


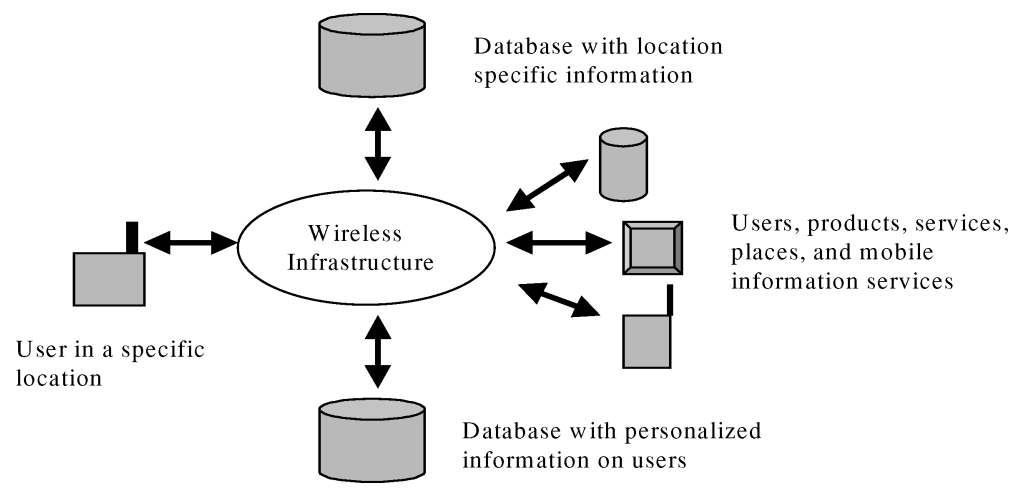

Fig. 4. Personalized location-based services.

A personalized location-based service architecture is shown in Figure 4. In this scenario, once a user enters a designated area, the user information from previous networks and locations will be accessed. The system will also determine what types of location-aware services this user has subscribed to or is authorized to access.

From an implementation point of view, several factors to consider are: (a) how to charge businesses for providing their location information to mobile users, (b) how to ensure correctness and usability of location information, (c) how to charge customers, and, (d) how to divide revenues among multiple wireless, location, and database providers.

Currently, there are a few examples of location-based services, not necessarily personalized or user-specific. Several location-based services are being offered by carriers such as mapping, routing, and list of places. Although not all of these offerings have become an instant success, there is considerable interest among users and businesses as several pricing options are offered. Vendors are offering to wireless service providers several fully functional location-based systems, including a Nortel system that is being deployed in several countries to support location-aware services to users and businesses [Nortel 2002]. There has also been some research and development work in location-based services. The location of a user is mapped to an area and then using Cellular Packet Digital Data (CDPD) base station numbering, services are searched in the area [Rastimor et al. 2001]. A service discovery, where bookmarks are mapped to Universal Resource Locator (URL) of services in the current location, has been implemented [Sastry at el. 2001]. Location changes are detected by applications and URLs are dynamically mapped. A secure location service has been implemented by using context and location awareness [Bisdikian et al. 2001].

\subsection{Specific Location Management Requirements of M-commerce Applications}

Location management requirements of $\mathrm{m}$-commerce applications can be expressed in terms of location accuracy, response time and priority, network coverage, number of devices involved, wireless dependability and reliability, type of communications, number of location queries per transaction, and, frequency 
and duration of transactions. Location accuracy depends on the radio characteristics, response time needed, level of mobility, network topology, and the positioning scheme used. Some applications require both horizontal as well as vertical positioning, speed and direction, and a certain confidence level with a location estimate. The location requirement is also likely to be time- and location-dependent.

Failures in a wireless infrastructure will greatly affect m-commerce applications. Failure of Home Location Register/Visitor Location Register (HLR/VLR) that stores approximate locations of wireless users will affect location-intensive applications [Varshney and Malloy 2001]. Location management should cover both indoor and outdoor tracking of people, products, and services. A user is more likely to need location information when roaming under another provider whose network may not have the same level of location performance. Some applications involve users and devices over several wireless networks of different location accuracies. A "minimum capability set" of each wireless network should be matched with minimum requirements of each m-commerce application.

Other issues in location management in mobile commerce applications are privacy and security, ownership of location information, device complexity and user interface, overhead of location-based services, development of business models for pricing and revenue sharing, vendor support, and service interoperability. Access to current location information of users raises both security and privacy issues. This potentially makes certain users vulnerable to security threats. A user could specify who could access such information in "normal" and "emergency" cases and also what and when some information can to be "pushed" to him/her. One issue is who owns the location information. Since a wireless carrier provides the first access point for most wireless users, it is likely to have such information. A user should be able to specify that such information can only be used by the wireless service provider and must not be distributed to others. However, a variety of information on products, services, and places could be aggregated and then location-sensitive and user-specific content can be created.

We now discuss specific requirements of the three location-intensive applications (Table I). Mobile financial services require the location tracking of financial institutions, mobile users, transaction servers, and devices that are capable of accepting micro-payments. Such an application would require location accuracy of the order of few meters. Since a few devices are likely to be involved in any financial transactions, unicast mode of information transfer could be used. Due to the potential value of financial transactions, dependability of wireless infrastructure would be a critical requirement. On average, a user is likely to make a few such transactions in a day and we believe that most users would finish such transactions in a few seconds.

Mobile and user-specific advertising applications present very different requirements, since mobile advertising needs to reach specific users served by one or more wireless networks and the same message has to be transmitted to multiple users. So, location management, multicast and roaming across multiple networks are required. Since these services need location information, a third party could be used for location services. Since the potential value of such 
Table I. M-commerce Applications and Location Requirements

\begin{tabular}{|c|c|c|c|}
\hline & $\begin{array}{l}\text { Mobile Financial } \\
\text { Applications }\end{array}$ & $\begin{array}{l}\text { Mobile and Locational } \\
\text { Advertising }\end{array}$ & $\begin{array}{c}\text { Personalized } \\
\text { location-based } \\
\text { services }\end{array}$ \\
\hline $\begin{array}{l}\text { Location Precision } \\
\text { (upper limit) }\end{array}$ & Meters (sub-cell) & $\begin{array}{l}\text { Hundreds of meters } \\
\text { (cell) }\end{array}$ & Meters (sub-cell) \\
\hline $\begin{array}{l}\text { Response time and } \\
\text { frequency per } \\
\text { transaction }\end{array}$ & $\begin{array}{c}\text { Seconds/few times } \\
\text { in a transaction }\end{array}$ & $\begin{array}{l}\text { Minutes/once in a } \\
\text { transaction }\end{array}$ & $\begin{array}{l}\text { Seconds/several } \\
\text { times in a } \\
\text { transaction } \\
\end{array}$ \\
\hline $\begin{array}{l}\text { Required Wireless } \\
\text { Network Coverage }\end{array}$ & Citywide & $\begin{array}{l}\text { Small area to } \\
\text { citywide }\end{array}$ & $\begin{array}{l}\text { Citywide to } \\
\text { nationwide }\end{array}$ \\
\hline $\begin{array}{l}\text { Number of devices } \\
\text { and entities } \\
\text { involved }\end{array}$ & Few & Several & Several \\
\hline $\begin{array}{l}\text { Information transfer } \\
\text { mode }\end{array}$ & Secured unicast & $\begin{array}{l}\text { Asymmetric } \\
\text { non-real-time } \\
\text { multicast }\end{array}$ & $\begin{array}{l}\text { Asymmetric } \\
\text { real-time unicast } \\
\text { or multicast }\end{array}$ \\
\hline $\begin{array}{l}\text { Wireless } \\
\text { dependability } \\
\text { requirement }\end{array}$ & Very high & $\begin{array}{c}\text { Can tolerate lower } \\
\text { dependability }\end{array}$ & High \\
\hline $\begin{array}{l}\text { Transaction frequency } \\
\text { and duration }\end{array}$ & $\begin{array}{l}\text { Once a day for few } \\
\text { seconds }\end{array}$ & $\begin{array}{l}\text { Few times a day for } \\
\text { few seconds }\end{array}$ & $\begin{array}{l}\text { Several times a day } \\
\text { for few minutes }\end{array}$ \\
\hline
\end{tabular}

advertisements is not as high as financial transactions, wireless dependability is not so crucial. However, to cover a significant number of users in a given area, as is needed in mobile advertising, wireless multicast support is very important. If such support is not available, either the number of users has to be limited or wireless networks will have to handle significantly increased traffic. On the positive side, since these advertisements could wait for seconds to minutes, real-time delivery is not necessary. Also users do not have to be precisely located as cell-level accuracy is sufficient for mobile advertising which is targeting users in a given area of approximately 1 mile or less.

Personalized location-based services introduce requirements that are likely to be somewhere in between financial applications and mobile advertising. The number of entities involved is likely to be more than that for financial applications but certainly lower than that for mobile advertising. The accuracy of information must be high but the wireless dependability requirement is likely to be lower than that required for financial applications. These requirements are presented and compared in Table I.

\section{AN INTEGRATED LOCATION MANAGEMENT ARCHITECTURE}

Having presented $\mathrm{m}$-commerce applications and their specific requirements, we now present an integrated location management architecture. The proposed architecture (Figure 5) consists of several heterogeneous wireless networks including satellites, cellular, PCS and 3G networks, and, wireless LANs and PANs to support diverse location requirements. These are location precision, wireless coverage, multicast, and wireless dependability. The location precision requirement can be satisfied by using one of several wireless networks, which 


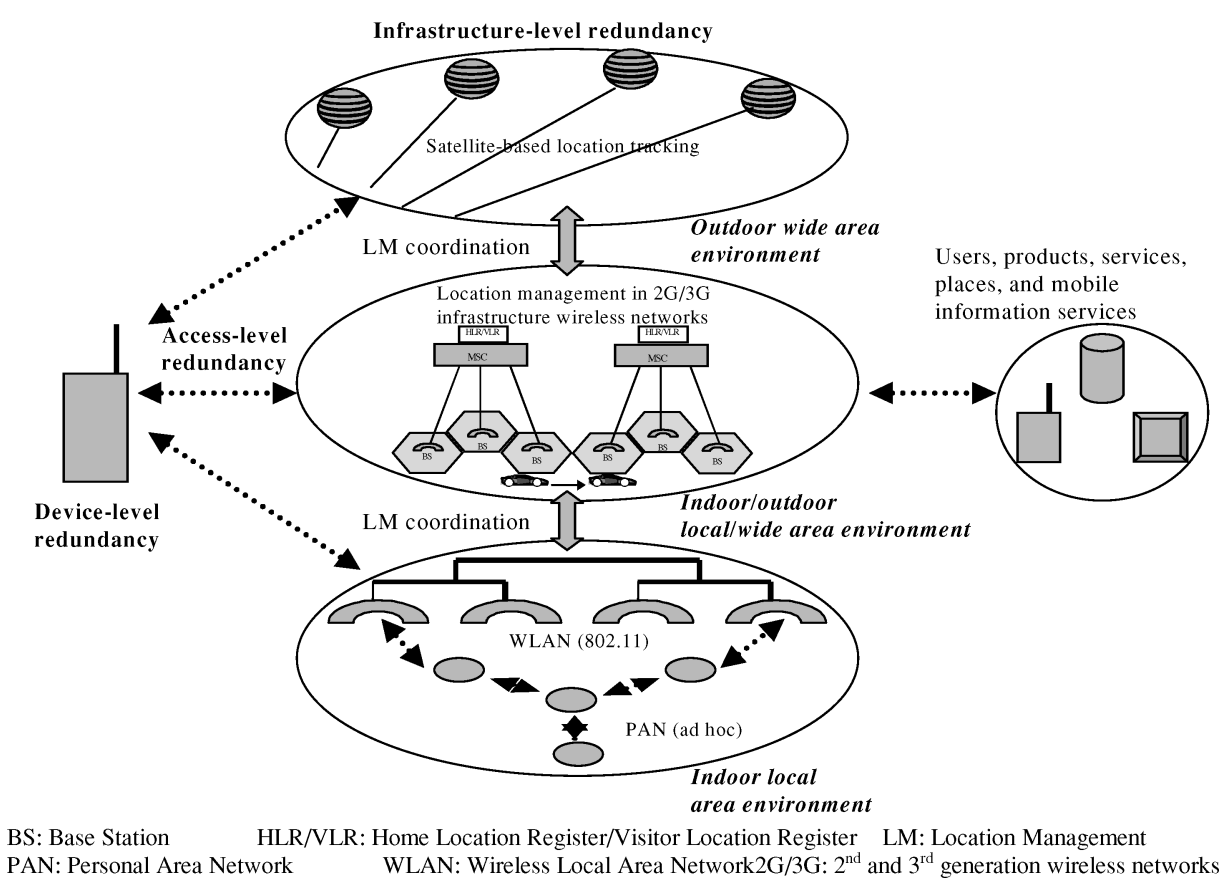

Fig. 5. The proposed integrated location management architecture.

provide different levels of location accuracy. An extensive wireless coverage is achieved by providing indoor and outdoor coverage to fixed and mobile users in local as well as wide area environments. Access to multiple wireless networks also enhances the infrastructure's dependability. The wireless multicast requirement is fairly complex and most current wireless networks are not designed to support multicast. In our proposed architecture, wireless multicast could be supported by satellite systems as well as by cellular 2G/3G systems using a selective broadcast or a tree-based multicast approach [Varshney 2002]. The wireless infrastructure dependability requirement is supported by faulttolerant operation at device, access and infrastructure levels. This requires that a user device be equipped with multiple network interfaces; however it provides fault-tolerant (highly dependable) operation for both user devices and networks. It is possible that a user is able to access only one network in a certain location at a certain time. Thus, the level of accuracy achieved is both time and location dependent. Other $\mathrm{m}$-commerce requirements are transaction frequency and duration, and response time. These are dependent on network traffic and would be addressed in our future work dealing with location management overhead and performance evaluation.

Since this architecture supports the roaming of a user across multiple networks, location co-ordination is necessary among networks. As shown in Figure 5, location tracking can also be performed using a wireless local area network (WLAN) or a personal area network (PAN). Since these networks cover smaller areas (and fewer users), a base station or a certain device can 


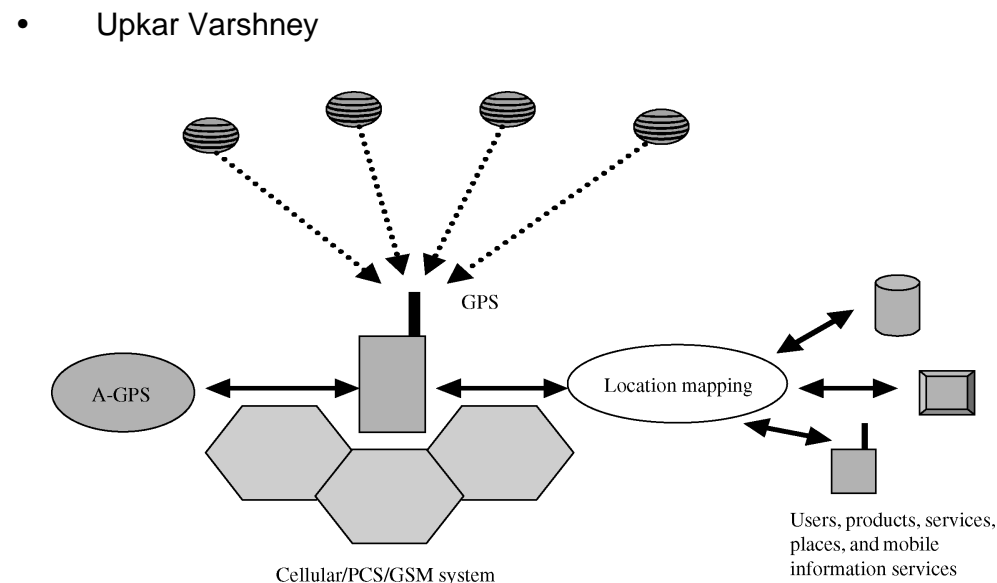

Fig. 6. Satellite-based systems for m-commerce applications.

be programmed to determine if a certain device or user is located in its coverage and this is applicable to both infrastructure and ad hoc versions.

Location tracking involves mobile, portable, or fixed entities. Mobile entities can be located within the accuracy of the location scheme of the wireless network(s) used. If mobile entities are part of an ad hoc wireless network, then a more specialized scheme (such as using GPS and a monitoring system) has to be used. Portable entities without regular wireless access can be tracked using radio frequency tags or a specialized locator device. Location information on fixed entities can be stored in a database and can be updated as necessary. As shown in Figure 5, a user with access to such infrastructure can locate devices, products, and location-aware mobile information services.

Now we describe the individual components of our proposed architecture. These include satellite-based systems, $2 \mathrm{G}$ and $3 \mathrm{G}$ networks, WLANs and PANs.

\subsection{Satellite-based Systems}

Satellite-based systems can be used for wide area location tracking. One such system is GPS (Global Positioning Satellite-system), where 24 satellites broadcast coded location information. The information is received and processed by GPS receivers to determine their locations. The location precision achieved is in the range of a few to several hundred meters. To reduce the complexity of user devices, assisted GPS system could be used. To improve location accuracy even further, differential GPS systems can also be deployed. In our proposed architecture, the GPS information could be mapped to a specific area and then used to receive location-based services as shown in Figure 6.

\subsection{Cellular Wireless Networks}

In cellular, PCS, and GSM, location tracking is done as follows: as long as the user stays in a certain location area, it does not update the location. However, once the user moves to a different location area, update messages are sent (Figure 7). In general, the network knows the location of users with accuracy equal to the size of the location area. Our proposed architecture achieves even higher accuracy by using a smaller location area with a reduced cell size and 


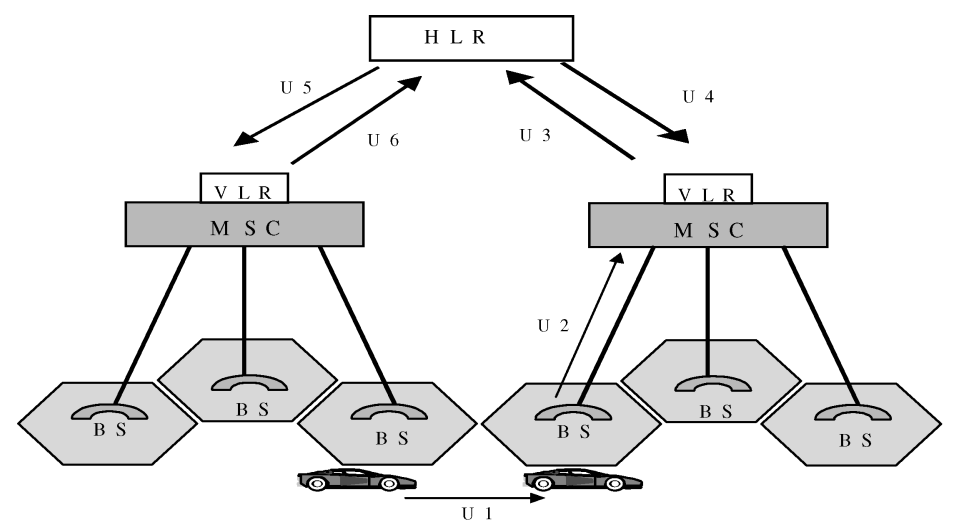

Location Update Steps

U1: User moving to new area $\quad$ U2: User registering with VLR U3: VLR sending request to HLR U4: HLR sending ACK to VLR U5:HLR informing the old VLR U6: Old VLR sending ACK to HLR

Fig. 7. Location tracking by current cellular wireless networks.

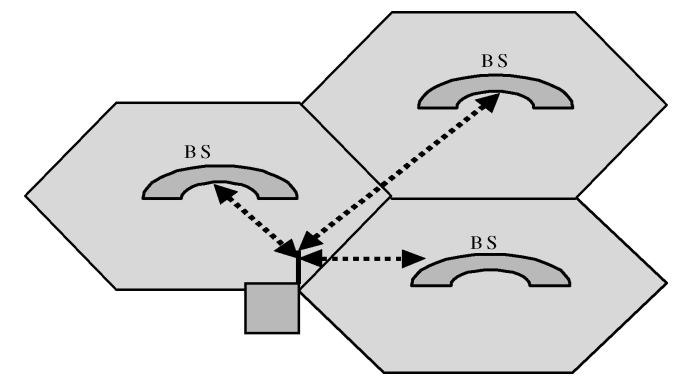

Fig. 8. Using small cells and base station triangulation to achieve precise location.

number of cells. The reduced number of cells allows accurate location information to be found quickly by paging fewer cells. In case an "immediate" tracking is needed with near-zero response time or when a user is inactive (or is in an area out of the network coverage), the network can return the last known location of the user.

Even higher precision of location could be supported by the emerging Enhanced 911 (E911) infrastructure that will allow network-based tracking with 100-meter precision and handset-based tracking with 50-meter for mobile users [FCC 2001]. The accuracy achieved for portable and fixed entities is even higher. Major E911 schemes are Assisted and Differential Global Positioning Systems (A-GPS and D-GPS), Time Difference of Arrival (TDOA), Angle of Arrival (AOA), and Location Pattern Matching (LPM) [Djuknic and Richton 2001]. TDOA and AOA schemes locate a mobile device by processing the difference in signal arrival times at three or more antenna sites, termed base station triangulation. Our architecture supports even higher location accuracy by combining small cells with base station triangulation as shown in Figure 8. 


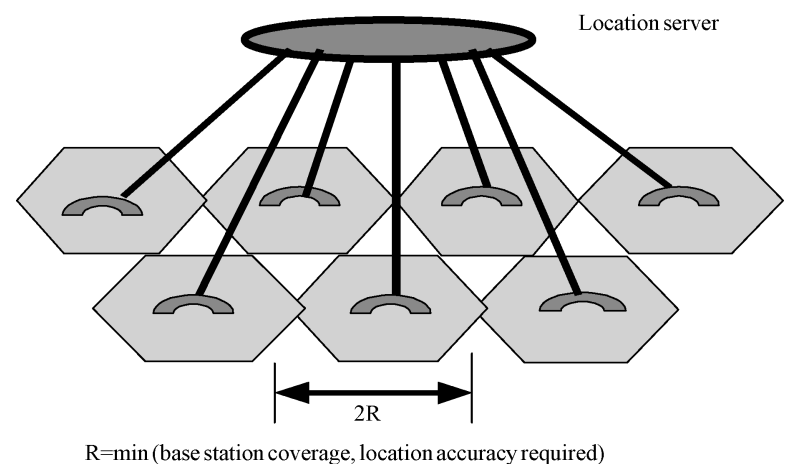

Fig. 9. Designing smaller wireless LANs for precise location tracking.

\subsection{WLANs, PANs and RFID}

Some of the cellular/PCS location schemes can be used in indoor location tracking. Since many indoor applications require higher location precision, we propose that smaller wireless local area networks (WLANs) and personal area networks (PANs) be used. In our proposed architecture, base stations are kept closer and these co-operate in location tracking of radio-enabled devices, users, products, and services. The radius of a cell can be determined as the minimum of location accuracy and the coverage of base stations as shown in Figure 9.

The last component of our proposed architecture is RFID (Radio Frequency Identification). It uses wireless links to uniquely identify objects or people using dedicated short-range communications [D'Hont 2001]. When a product or person with a tag enters the read zone of a reader, the address and data stored on the tag is read and can be sent to a server for location-tracking purposes. Since RFID readers have limited coverage (5-10 feet), our proposed architecture includes a multidimensional grid of RFID readers to cover the whole area (such as a warehouse). This would detect both horizontal and vertical location of components, products and people with RFID tags. The maximum distance between two neighboring readers can be based on the range of readers and the location accuracy required as shown in Figure 10.

Another interesting way to perform indoor location tracking is via using specialized location devices attached to products and people. One such example is Locus that can be attached to clothes or portable devices [Koshima and Hoshen 2000]. Such location terminals can return signal strength data and IDs of base stations to a monitoring center. Using this information, the user location can be computed to a varying degree of accuracy.

\section{USING THE PROPOSED ARCHITECTURE TO SUPPORT FUTURE M-COMMERCE APPLICATIONS}

In this section, we discuss how the proposed architecture could be used to support future mobile commerce applications such as product recommendation systems, wireless re-engineering, and mobile auction. As these applications are yet to be offered by wireless carriers or content providers, it is much harder to derive their specific location requirements. But, in any case, we attempt to 


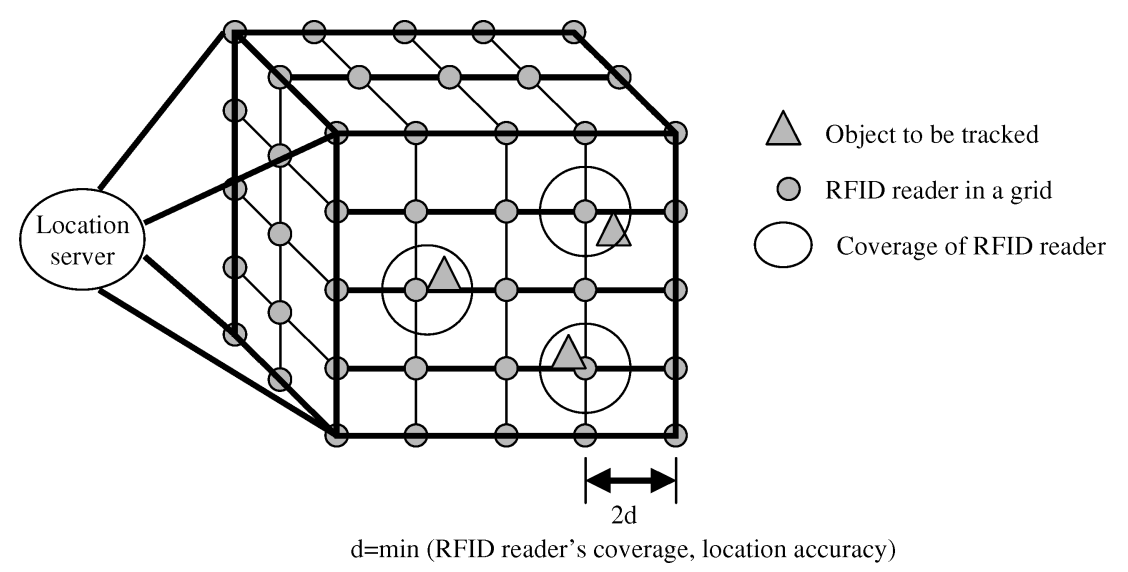

Fig. 10. Designing RFID-based grid for location accuracy.

derive the general requirements of these applications and then discuss how our proposed location management architecture is capable of supporting these emerging and future m-commerce applications.

\subsection{Future M-commerce Applications}

Wireless Re-engineering includes applications that focus on improving the quality of business services using mobile devices and wireless infrastructure. An example of such application is instant claim-payments by insurance companies [Varshney and Vetter 2002].

Mobile Auction and Wireless Trading includes applications that allow users to buy or sell certain items using multicast support of wireless infrastructure. These applications require that group membership not be adversely affected by brief wireless disconnectivity or intermittent connectivity as observed in many wireless networks of today. An example could be airplanes competing to buy a landing time slot during runway congestion (a proposed solution to air-traffic congestion problem).

Product Recommendation includes applications allowing users/businesses to receive recommendation of various products and services from a third party/other customers. Since there is a potential for conflict-of-interest from certain sets of users, some guidelines are necessary to create user trust before such applications become reality.

Mobile Entertainment Services and Games (B2C) are applications providing entertainment services to users on a per event or subscription basis. These include video-on-demand, audio-on-demand, and interactive games. It appears that mobile games will become one of the drivers of the wireless Internet, especially if group connectivity and response time issues can be addressed.

Mobile Office is an application providing a complete office environment to mobile users anywhere anytime including traffic jams, airport, and conferences. Although not as exciting as many other mobile applications, this is a useful application for business travelers and workers on the move. 
Mobile Distance Education extends distance/virtual education support for mobile users everywhere allowing a class using streaming audio and video. This application would be very useful if user mobility could be supported over one or more wireless networks to allow for continued connectivity.

Wireless Data Center application supports a large amount of stored data to be made available to mobile users for making "intelligent" decisions as detailed information on one or more products can be downloaded. It is an important application that is quite appealing to managers and decision makers who have to make certain decisions while on the move and under time pressure.

Wireless re-engineering, mobile office and wireless data center applications have similar requirements and thus we will discuss these together. These applications require a cell level (hundreds of meters) location accuracy, very high wireless dependability, wide coverage, and unicast operation for transactions that involve few devices and need response time of a few seconds. Mobile auction application requires similar location accuracy and dependability; however, it needs real-time wireless multicast involving a number of users spread over a possibly large area. Also, the transactions will last for several minutes and possibly longer. Mobile entertainment services and games, and mobile distance education have similar requirements. These applications also require cell level location accuracy, but dependability requirements are not very high. These applications require real-time wireless multicast; however, the amount of information flow in two opposite directions are likely to be quite different. All of these requirements can easily be met by the proposed location management architecture, which supports various degrees of location precision, wireless dependability, coverage, and multicast.

\subsection{Supporting Future M-commerce Applications}

We now discuss how our proposed architecture can support the above requirements. The diverse location precision of different $\mathrm{m}$-commerce applications can be obtained by carefully selecting and using one of the several wireless networks as shown in Figure 5.

Outdoor tracking support for m-commerce applications may be provided by either a cellular/PCS system or a satellite-based system such as assisted GPS. Nearly all the schemes used in cellular and satellite-based networks do well in an outdoor environment. Even wireless LANs and RFID-based systems could support applications requiring outdoor location management. Many of the proposed outdoor schemes will encounter performance problems in indoor environment due to triangulation difficulties caused by weaker signals and line of sight requirements of satellite-based schemes. Since many indoor tracking applications require higher location precision, smaller wireless local area networks (WLANs) and personal area networks (PANs) should be used for indoor location management. Indoor tracking for $\mathrm{m}$-commerce could be performed using specialized cells (where a base station can locate in a very small area, but a significant number of base stations are required to cover the whole area), wireless LANs, ad hoc personal area networks (PANs), and, Radio Frequency ID (RFID). 


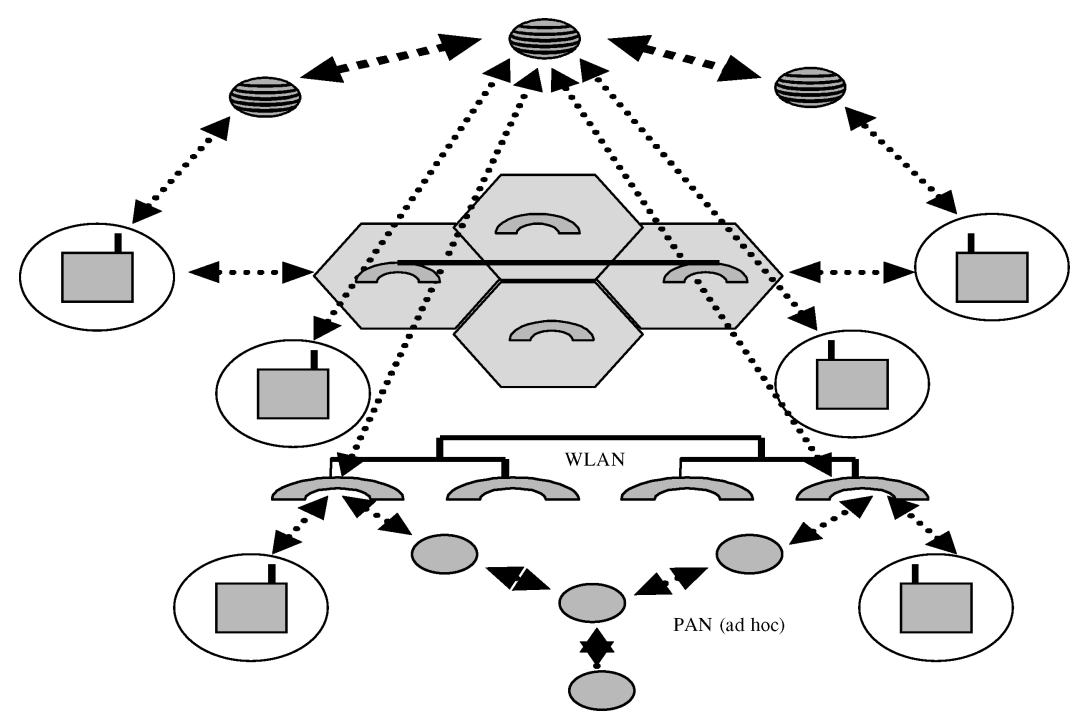

Fig. 11. Multicast support in the proposed architecture.

One of the requirements of $\mathrm{m}$-commerce applications is wireless multicast support. This is necessary for applications involving multiple users and entities. The current wireless infrastructure was not designed for such support; however, our proposed location management architecture can support multicast as shown in Figure 11. This architecture can support multicast in both connection-oriented as well as connection-less mode. These modes will facilitate "group-oriented" m-commerce applications that may require long sessions (such as mobile multiparty games) and short sessions (mobile advertising or location-based services), respectively.

The service providers must ensure that users, products, and services are covered by one or more wireless networks. Such coverage will require that wireless networks from multiple providers are interoperable. Also, in near future, a mobile user will require roaming support across several different types of wireless networks as opposed to several networks of the same type today. In such case, location co-ordination will be necessary among heterogeneous wireless networks.

Depending on the network architecture, all location requests go to a location server. In our proposed solution, the middleware negotiates or requests specific requirements (precision, response time, etc.) from multiple networks or schemes as shown in Figure 12. The middleware can translate application's requirements into specific location attributes such as location precision and response time for the underlying wireless infrastructure. It can also translate network performance attributes into specific requirement support. These capabilities are required for negotiating application's requirement and selecting a location scheme. The protocol and steps used by the middleware are shown in Figure 13. Also, as one or more wireless networks may have limited resources, a trade-off between the number of users needing location tracking and possible response time (or accuracy) would have to be made. 


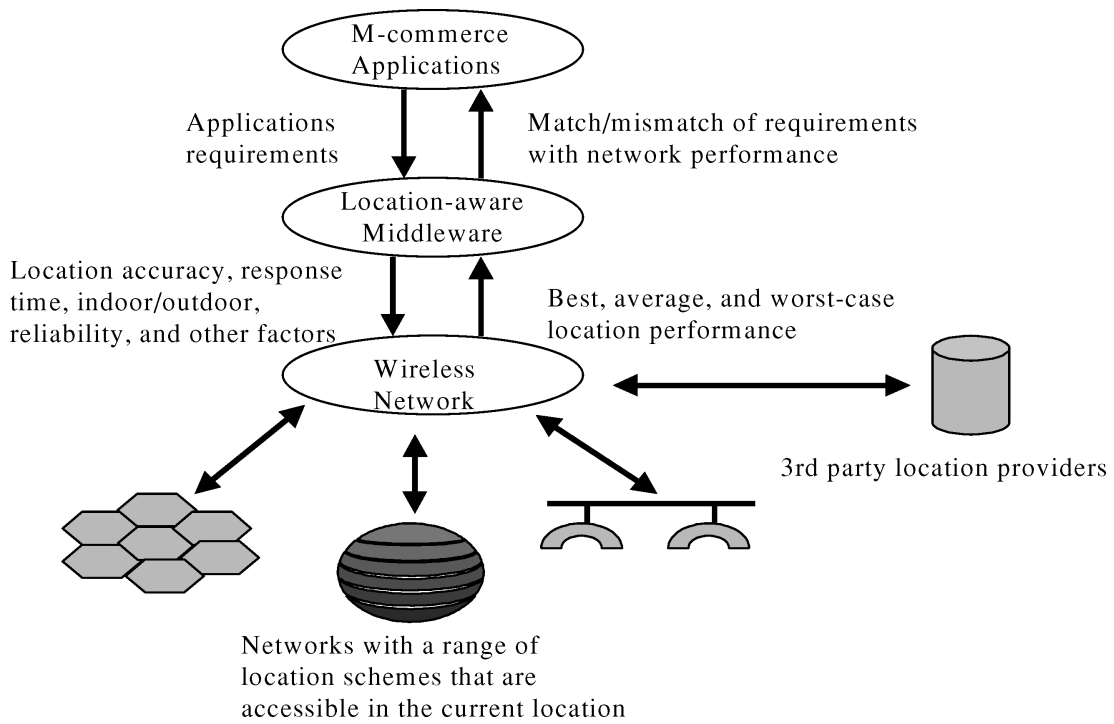

Fig. 12. Selecting a location scheme or network using applications requirements.

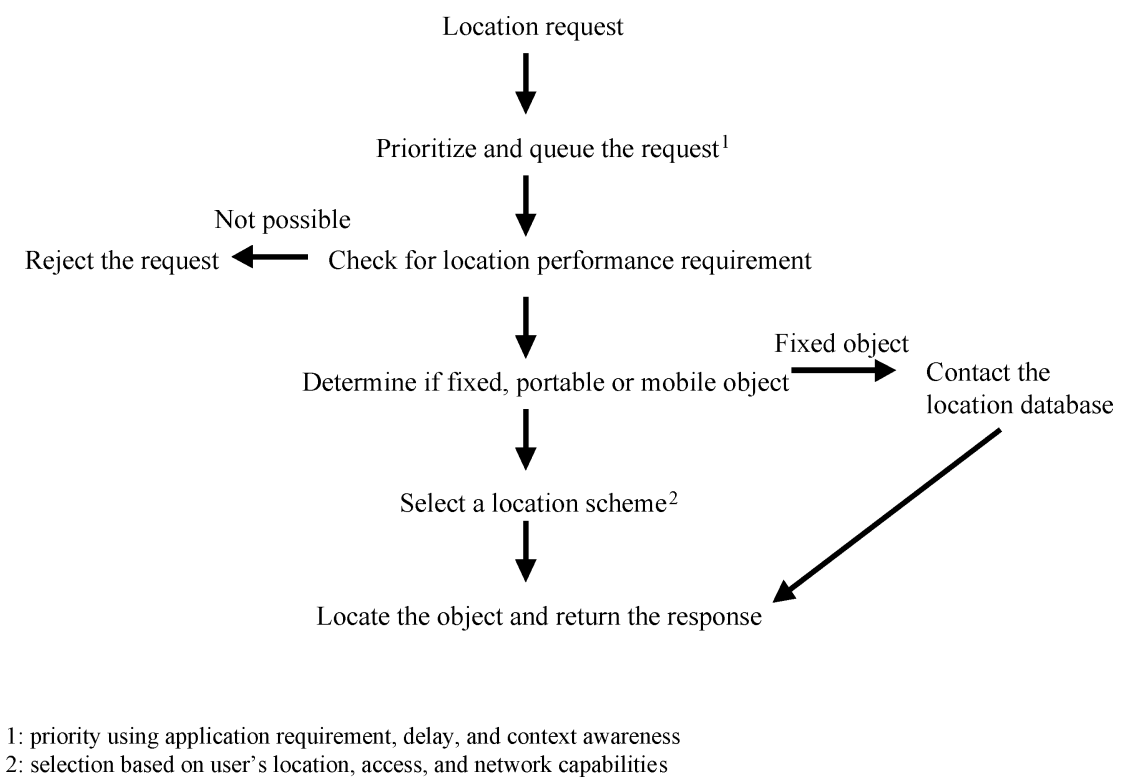

Fig. 13. The protocol used by middleware in the location management architecture.

Middleware should also negotiate support for location management even when the user is out of its home network while roaming to another network. The network will have very different location accuracy, response time, location scheme and format in which the location information is presented. To make things more difficult, the location information requested by the roaming user 
for its own location or for locations offering certain services and products is more likely to be needed and is certainly more critical.

\section{RESEARCH ISSUES AND FUTURE DIRECTIONS IN LOCATION MANAGEMENT}

After discussing the requirements of $\mathrm{m}$-commerce applications and our proposed location management architecture, we now turn to several interesting research problems related to location management in a wireless Internet. We will discuss application-specific design of location management schemes, computation of location management overhead, scalability and related issues in location-intensive mobile commerce applications.

The design of application-specific location management schemes could be based on specific location requirements (such as required location accuracy and response time) of one or more applications. Then signaling, processing and storage requirements of location scheme could be computed. On the other hand, locational attributes of an underlying wireless networks could be considered in deciding which of the several classes of mobile commerce applications could be supported. Applications that could not be easily supported by a given location scheme could be modified or redesigned to work with lower than expected performance such as reduced precision, increased delays or limited number of users. Applications could adjust to lesser attributes of the underlying network, especially when a mobile user is roaming across multiple heterogeneous wireless networks as supported by the emerging wireless standards.

The location management overhead of m-commerce applications can be estimated by modeling or simulating applications in terms of location precision, response time, transactions frequency, update rate and transaction duration, number of entities involved and the coverage needed. Such modeling will require individual steps of m-commerce applications in both "push" or "pull" versions. In "push" version, the network or a server initiates a transaction based on the current time (network pushes some information every hour), user's current location (whenever the user comes within a mile of a store, network sends an advertising message), or a threshold using context awareness and other user specific information.

Scalability of various location-intensive mobile commerce applications could be determined by network resources, the maximum number of concurrent location requests, the desired response time, and the number of transactions. Interoperability issue will become important as some m-commerce applications involve multiple networks that provide different location performance. In such cases, interoperability must be ensured by agreeing on "minimum common functionalities".

As locational resource requirements of some applications could exceed network resources and device capabilities, implementability issues should be carefully addressed. The requirements can be measured using simulation tools and then the applications can be scaled-down or simplified to enhance implementability. Such flexibility in various $\mathrm{m}$-commerce applications will allow 
working with reduced locational accuracy, increased response time, reduced reliability and other factors.

Another interesting problem is context awareness. Context awareness could be used in deciding if certain actions (such as pushing advertising information) should be completed at certain time. It is difficult to derive context awareness, but it is possible to use recent user actions in deriving a context.

\section{CONCLUSIONS}

In this article, we have presented the requirements of several location-intensive mobile commerce applications and an integrated location management architecture to support these requirements. The proposed architecture is shown to be capable of supporting diverse requirements of $\mathrm{m}$-commerce applications in terms of location accuracy, wireless multicast, dependability, response time, and wireless coverage. We also showed how the proposed location architecture could be used to support future m-commerce applications. Our future research work includes location co-ordination among multiple wireless networks, location negotiation protocols for $\mathrm{m}$-commerce, evaluation of $\mathrm{m}$-commerce locational overhead, prioritization of location requests based on applications requirements, context (emergency, anxiety, etc), and processing delays. Other open research issues are interoperability, implementability, middleware support, and context awareness. We hope that many of the above issues will be addressed in the near future, enabling the wide scale deployment of wireless Internet applications and services.

\section{ACKNOWLEDGMENTS}

I would also like to express my deep appreciation for Prof. Won Kim, Editorin-Chief, TOIT for his extremely valuable feedback to early versions of this article. Many thanks also go to Prof. Ron Vetter of University of North CarolinaWilmington for his suggestions to improve the readability of this article.

\section{REFERENCES}

Allnetdevices. 2002. Mobile Payments Set to Soar. (www.allnetdevices.com/wireless/news/2002/ 02/07/study_mobile.html).

Bisdikian, C., Christensen, J., Davis II, J., Ebling, M. R., Hunt, G., Jerome, W., Lei, H., Maes, S., And Sow, D. 2001. Enabling location-based applications, In Proceedings of the 1st ACM International Workshop on Mobile Commerce (Rome, Italy). ACM, New York, 38-42.

Cousins, K. And VARShney, U. 2001. Location management in B2B mobile commerce environment, In Proceedings of the 1st ACM International Workshop on Mobile Commerce (Rome, Italy, July). ACM, New York, 43-48.

D' HONT, S. 2001. The cutting edge of RFID technology and applications for manufacturing and distribution. A Texas Instruments White Paper (available at http://www.ti.com/tiris/docs/ manuals/whtPapers/manuf_dist.pdf)

Diercks, R. 2001. Mobile advertising: Not as bad as you think, Wireless Internet Mag. (JulyAugust) (available at www.wirelessinternetmag.com/news/0108/0108_research_ads.htm).

FCC ENHANCED 911(www.fcc.gov/e911).

DJuknic, G. ANd Richton, R. 2001. Geolocation and assisted GPS, IEEE Comput. 34, 2, 123-125.

Fichtner, H., 2002. Marketing via mobile phone: Coupons conquer the mobile phone, Acquisa (available http://www.evision-ventures.de/eng/news/029.html).

Financial Services Technology Corporation (www.fstc.org).

ACM Transactions on Internet Technology, Vol. 3, No. 3, August 2003. 
Ghosh, K. A. and Swaminatha, T. N. 2001. Software security and privacy risks in mobile e-commerce. Commun. ACM 44, 2, 51-57.

Goodman, D. 2000. The wireless Internet: promises and challenges. IEEE Computer 33, 7, 36-41. Koshima, H. ANd Hoshen, J. 2000. Personal locator services emerge. IEEE Spectrum 37, 2, 41-48. Mobile Marketing Association (www.mmaglobal.com).

Nortel's Mobile Location Services Solution. 2002. (www.nortelnetworks.com/corporate/news/ newsreleases/2002c/07_02_02_wollongong_mlc.html).

Paybox (www.paybox.net).

Rastimor, O., Korolev, V., Joshi, A., And Finin T. 2001. Agents2Go: An infrastructure for locationdependent service discovery in the mobile electronic commerce environment. In Proceedings of the 1st ACM International Workshop on Mobile Commerce (Rome, Italy, July). ACM, New York, $31-37$

Sastry, D., Cole, A., Munson, J., And Christensen, J. 2001. An approach to providing a seamless end-user experience for location-aware applications. In Proceedings of the 1st ACM International Workshop on Mobile Commerce (Rome, Italy, July). ACM, New York, 20-25.

Sprint and eone Mobile Payment Network. 2002. (www.mcommercetimes.com/Services/254).

Tracz R. and Wrona, K. 2001. Fair electronic cash withdrawal and change return for wireless networks. In Proceedings of the 1st ACM International Workshop on Mobile Commerce (Rome, Italy, July). ACM, New York, 14-19.

VARShNey, U. 2001. Addressing location management issues in mobile commerce, In Proceedings of IEEE Conference on Local Computer Networks (LCN-26) (Tampa, Fla., Nov.). 184-192.

VARShNEY, U. 2002. Mobile commerce: Issues, technologies, and solutions, A tutorial at ACM International Conference on Mobile Computing and Networking (Mobicom) (Atlanta, Ga., Sept.) ACM, New York.

VARShNey, U. AND Malloy, A. 2001. An integrated approach for improving the dependability of the emerging wireless networks. In Proceedings of IEEE International Conference on Global Communications (Globecom) (San Antonio, Tex., Nov.) IEEE Computer Society Press, Los Alamitos, Calif., 3693-3697.

VARShNEY, U. AND VETtER, R. 2002. Mobile commerce: Applications, frameworks, and networking support. ACM / Kluwer J. Mob. Netw. Appl. (MONET) 7, 3, 185-198.

Varshney, U., Vetter, R., and Kalakota, R. 2000. Mobile commerce: A new frontier. IEEE Computer $33,10,32-38$.

Vodafone Mobile Payment System. 2002. (www.pcmag.co.uk/News/1128273).

Received June 2002; revised July 2002, August 2002, January 2003; accepted February 2003 